\title{
PENGEMBANGAN PERMAINAN SUNDA MANDA PUZZLE UNTUK OPTIMALISASI KEMAMPUAN MOTORIK DAN PEMBENTUKAN KARAKTER CERMAT DALAM PEMBELAJARAN PENJASORKES DI SD
}

\author{
(Sunda Manda Puzzle Game Development For Optimization Of Motor Abilities \\ And Careful Character Formation In Physical Education Learning In \\ Elementary School)
}

\author{
Kusmiyati $^{1}$, Restian Gigih Sejati ${ }^{2}$, Ruman $^{3}$ \\ Pendidikan Jasmani Kesehatan dan Rekreasi, STKIP Darussalam Cilacap ${ }^{1,2,3}$
}

$\underline{\text { kusmiyatinsw@yahoo.co.id }}{ }^{1}$, gigiholahraga@gmail.com ${ }^{2}, \underline{\text { ruman817@ @mail.com }}^{3}$

\begin{abstract}
ABSTRAK
Penelitian ini bertujuan menghasilkan model permainan sunda manda puzzle untuk mengoptimalkan kemampuan motorik dan pembentukan karakter cermat dalam pembelajaran penjasorkes di Sekolah Dasar. Prosedur pengembangan meliputi beberapa tahapan: (1) tahap pendahuluan, (2) tahap pengembangan, (3) tahap uji model. Hasil penelitian ini berupa produk permainan sunda manda puzzle yang dapat digunakan oleh guru penjasorkes di Sekolah Dasar sebagai media pembelajaran khususnya dalam materi permainan tradisional. Kesimpulan penelitian: (1) Hasil reliabilitas untuk respon guru Penjasorkes dikatakan reliabel karena $r$ hitung $>r$ tabel yaitu 1,823 dengan taraf signifikan 5\%. (2) Data responden siswa sebagai penguat dalam penilaian yang diambil dengan indikator kognitif sebesar 97,34\%, Indikator afektif sebesar 91,96\%, serta Indikator psikomotor sebesar 93,43\%, (3) rata-rata kenaikan jumlah denyut nadi setelah pembelajaran permainan sunda manda puzzle sebesar 64,01\%. Dengan demikian produk akhir Pengembangan permainan sunda manda puzzle untuk optimalisasi kemampuan motorik dan pembentukan karakter cermat dalam pembelajaran penjasorkes di Sekolah Dasar sesuai dengan karakteristik siswa Sekolah Dasar dan efektif digunakan dalam pembelajaran penjasorkes.
\end{abstract}

Kata Kunci : Sunda Manda, Kemampuan Motorik, dan Karakter Cermat.

\begin{abstract}
This study aims to produse a sunda manda puzzle game model to optimize motor skills and careful character formation in phsical education learning in elementary schools. The development procedure includes several stages: (1) preliminary stage, (2) development stage, (3) model test stage. The result of this research are the product of the sunda manda puzzle game that can be used by phsyical education teachers in elementary schools as a learning medium, especially traditional games. The conclusions of the study: (1) The reliability result for the responses of physical education teachers are said to be reliable because they are > 1.823 with significant level of $5 \%$. (2) student respondent data as reinforcement in the assessment taken with cognitive indicators of $97,34 \%$, affective indicators of $91,96 \%$, psychomotor indicators of $93,43 \%$, (3) the average increase in the number of pulses after learning the sunda manda puzzle game was 64,01\%. Thus the final product of the development of the sunda manda puzzle game to optimize motor skills and the formation of careful character in physical education learning in elementary schools is in accordance with the characteristics of elementary school students and is effectively used in physical education learning.
\end{abstract}

Keywords: Sunda Manda, Motor Skills, and Careful Charakter.

Dipublikasikan Oleh :

UPT Publikasi dan Pengelolaan Jurnal

Universitas Islam Kalimantan Muhammad Arsyad Al-Banjari Banjarmasin 


\section{PENDAHULUAN}

Pendidikan jasmani adalah proses pendidikan melalui aktivitas jasmani, permainan atau olahraga yang terpilih untuk mencapai tujuan pendidikan (Dini Rosdiani 2013:138).Tujuan utama pembelajaran pendidikan jasmani olahraga dan kesehatan di sekolah dasar adalah untuk membantu agar peserta didik meningkatkan kemampuan geraknya.Tujuan lainnya juga supaya mereka terdorong untuk melakukan berbagai aktivitas. Keterampilan bermain merupakan salah satu faktor untuk mendukung tumbuh kembang pada anak-anak, terutama pada fase anak usia sekolah dasar. Bermain merupakan cara bagi anak-anak untuk mengekspresikan potensi secar fisik, mental dan sosio-emosional. Beramain apapun sebenarnya sangat penting selain untuk pertumbuhan dan perkembangan anak juga untuk membentuk karakter cermat dalam melakukan permainan.

"Sebagaimana pendapat Newman seperti telah dikutip Agus Sumanto (2010:1) berpendapat bahwa " bermain merupakan penyaluran bagi ekspresi energi yang berlebihan. Bagi anak-anak, menyalurkan energi dilakukan dengan cara bermain"(Kusmiyati et al., 2014). Dalam kegembiraan bermain, berpetualang, dan mengeksplorasi lingkungan, anak-anak juga tengah mengembangkan berbagai jenis kecerdasan dan mempraktikan beragam keterampilan hidup yang sangat berguna bagi kehidupan mereka kelak (Achroni, 2012:5).

Salah satu materi penjasorkes di sekolah dasar adalah pemainan tradisional.Beragam permainan tradisional memang mampu menjadi media untuk mengoptimalkan berbagai kecerdasan kognitif, kecerdasan sosial, kecerdasan musikal, kecerdasan kinestetik, kecerdasan linguistik, kecerdasan spiritual, hingga mengajarkan berbagai nilai positif dan menyehatkan badan (Achroni, 2012:6).Akan tetapi permainan tadisional saat ini mulai ditinggalkan oleh anak-anak, bahkan mereka sudah tidak mengenal permainan tersebut. Hal ini disebabkan bentuk atau cara bermainnya yang kurang menarik bagi anak-anak disisi lain disebabkan oleh faktor perilaku kehidupan yang modern dengan ditandai kebiasaan anak kurang gerak. Anak lebih menyukai permainan play station, game online atau gadget.

Permainan tradisional Sunda Manda merupakan permainan populer pada usia anak-anak yang menjadi warisan budaya nenek moyang. Terdapat beberapa kandungan potensial yang memiliki nilai pengembangan pada ranah kemampuan motorik maupun sebagai instrumen pembentukan karakter pada anak-anak. Toho Cholik Mutohir, (2011:70) berpendapat bahwa Menanamkan dan mengembangkan pendidikan karakter melalui olahraga mengenalkan, memberikan pemahaman, mendorong kepada pelaku olahraga untuk mempraktikan empat pilar karakter dalam permainan dan olahraga yang dipraktikan dalam kegiatan olahraga sehari-hari ketika berinteraksi dengan teman sepermainan. Inti dari aplikasi pendekatan melalui olahraga adalah terintegrasi yang dirancang oleh guru olahraga dan dipraktikan dalam kehidupan seharihari.

Sunda Manda atau disebut engklek adalah salah satu jenis permainan tradisional yang popular di Indonesia, khususnya di masyarakat pedesaan. Permainan Sunda Manda biasanya dimainkan oleh anak-anak dengan dua sampai lima peserta. Adapun manfaat permainan Sunda Manda yaitu, (1) Melatih motorik kasar, (2) Sunda Manda mengajak anak untuk berolahraga sambil bermain. (3) sarana olahraga yang menyehatkan, (4) melatih berfikir kreatif, (5) melatih sosialisasi.

\section{METODE PENELITIAN}

Penelitian ini adalah penelitian pengembangan. Jenis penelitian dan pengembangan merupakan penelitian yang digunakan untuk menghasilkan produk tertentu dan menguji keefektifan produk tersebut, (Arikunto, Suharsimi, 2010) Ada tiga tahapan motode R \& D menurut (Sukmadinata, 2010:184) yaitu; (1) tahap pendahuluan, (2) tahap pengembangan, (3) tahap uji model.

Adapun teknik analisis yang digunakan adalah menggunakan teknik analisis deskriptif kualitatif dan kuantitatif. Analisis data kualitatif peneliti menggunakan model interaktif dari Miles dan Huberman (Miles dan Huberman, 2014). Adapun model interaktif yang dimaksud sebagai berikut:

Dipublikasikan Oleh : 


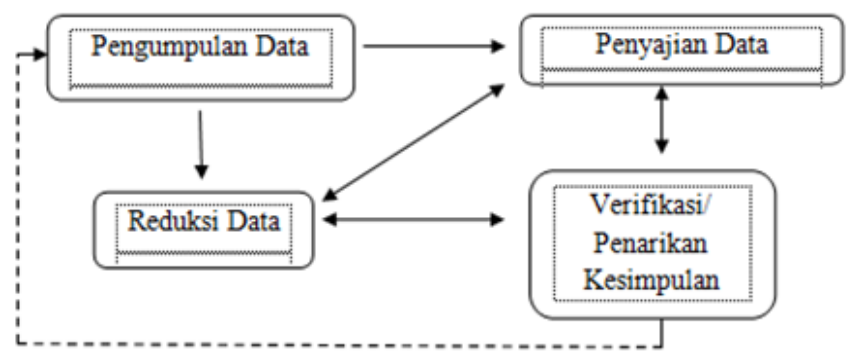

Bagan 1. Model analisis data interaktif

Sedangkan Analisis data kuantitatif (keefektifan produk) menggunakan uji-t untuk mengetahui perbedaan atau pengaruhnya. Analisis uji-t yang digunakan adalah dengan menggunakan bantuan program computer paket Seri Program SPSS-16 dengan taraf signifikansi 5\%.Teknik analisis yang digunakan adalah porsentase untuk menganalisis dan penilaian subyek pengembangan dalam menilai tingkat kelayakan, kualitas dan keterterimaan produk (kegunaan dan relevansi) terhadap produk pengembangan dengan rumus:

$$
\begin{aligned}
& \mathrm{P}=\frac{f}{N} \times 100 \% \\
& \text { Keterangan: } \mathrm{f}=\text { Frekuensi subyek } \\
& \mathrm{N}=\text { Jumlah keseluruhan }
\end{aligned}
$$

\section{HASIL DAN PEMBAHASAN}

Hasil penelitian pengembangan permainan sunda manda puzzle

untuk optimalisasi kemampuan motorik dan pembentukan karakter cermat dalam pembelajaran penjasorkes di SD ditunjukan pada table dibawah ini :

\begin{tabular}{|c|c|c|c|c|c|c|}
\hline Aspek & $\begin{array}{l}\text { Butir } \\
\text { Soal }\end{array}$ & $\begin{array}{c}\text { Ju } \\
\text { mlah } \\
\text { Siswa }\end{array}$ & $\begin{array}{l}\text { Ju } \\
\text { mlah } \\
\text { Positif }\end{array}$ & $\begin{array}{c}\text { Ju } \\
\text { mlah } \\
\text { Negatif }\end{array}$ & $\begin{array}{r}\% \\
\text { Positif }\end{array}$ & $\begin{array}{r}\% \\
\mathrm{Ne} \\
\text { gatif }\end{array}$ \\
\hline \begin{tabular}{lr}
\multicolumn{2}{c}{ Keterterimaan } \\
siswa & terhadap \\
produk permainan \\
sunda manda puzzle
\end{tabular} & $1-10$ & 79 & $7^{295}$ & 203 &, 58 & 6,4 \\
\hline
\end{tabular}

Tabel 1. Keterterimaan respon siswa terhadap produk permainan sunda manda puzzle

\begin{tabular}{|c|c|c|c|c|c|c|}
\hline Aspek & $\begin{array}{c}\text { Butir } \\
\text { Soal }\end{array}$ & $\begin{array}{c}\text { Ju } \\
\text { mlah } \\
\text { Siswa }\end{array}$ & \begin{tabular}{l}
\multicolumn{1}{c}{ Ju } \\
mlah \\
Positif
\end{tabular} & $\begin{array}{c}\text { Ju } \\
\text { mlah } \\
\text { Negatif }\end{array}$ & $\begin{array}{r}\% \\
\text { Positif }\end{array}$ & $\begin{array}{r}\% \\
\text { Ne } \\
\text { gatif }\end{array}$ \\
\hline
\end{tabular}

Tabel 2. Respon siswa setelah menggunakan permainan sunda manda puzzle terhadap aspek Indikator kognitif

Dipublikasikan Oleh :

UPT Publikasi dan Pengelolaan Jurnal

Universitas Islam Kalimantan Muhammad Arsyad Al-Banjari Banjarmasin 


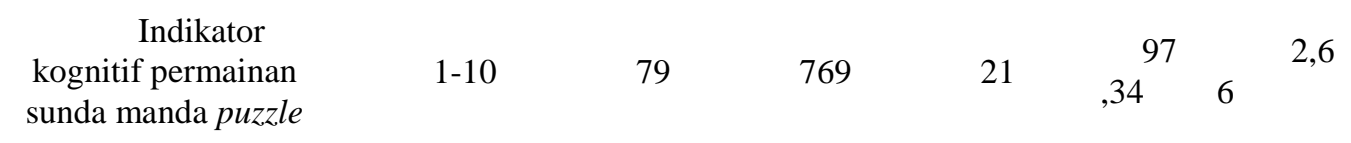

Tabel 3. Respon siswa setelah menggunakan permainan sunda manda puzzle terhadap aspek Indikator Psikomotor

\begin{tabular}{|c|c|c|c|c|c|c|}
\hline Aspek & $\begin{array}{l}\text { Butir } \\
\text { Soal }\end{array}$ & $\begin{array}{l}\text { Ju } \\
\text { mlah } \\
\text { Siswa }\end{array}$ & $\begin{array}{l}\text { Ju } \\
\text { mlah } \\
\text { Positif }\end{array}$ & $\begin{array}{c}\text { Ju } \\
\text { mlah } \\
\text { Negatif }\end{array}$ & $\begin{array}{r}\% \\
\text { Positif }\end{array}$ & $\begin{array}{r}\% \\
\text { Ne } \\
\text { gatif }\end{array}$ \\
\hline $\begin{array}{l}\text { Indikator } \\
\text { psikomotor } \\
\text { permainan sunda } \\
\text { manda puzzle }\end{array}$ & $1-4$ & 79 & $1^{118}$ & 83 & $\begin{array}{r}93 \\
, 43\end{array}$ & 6,5 \\
\hline
\end{tabular}

Tabel 4. Respon siswa setelah menggunakan permainan sunda manda puzzle terhadap aspek Indikator Afektif

\begin{tabular}{|c|c|c|c|c|c|c|}
\hline Aspek & $\begin{array}{l}\text { Buti } \\
\text { r Soal }\end{array}$ & $\begin{array}{r}\text { Juml } \\
\text { ah Siswa }\end{array}$ & $\begin{array}{l}\text { Ju } \\
\text { mlah } \\
\text { Positif }\end{array}$ & $\begin{array}{c}\text { Jum } \\
\text { lah } \\
\text { Negatif }\end{array}$ & $\begin{array}{r}\% \\
\text { Positif }\end{array}$ & $\begin{array}{r}\% \\
\mathrm{Ne} \\
\text { gatif }\end{array}$ \\
\hline $\begin{array}{c}\text { Indikator } \\
\text { Afektif permainan } \\
\text { sunda manda } \\
\text { puzzle }\end{array}$ & $1-5$ & 79 & $5^{149}$ & 85 & $\begin{array}{r}94 \\
, 62\end{array}$ & 5,3 \\
\hline
\end{tabular}

\section{PEMBAHASAN}

Berdasarkan langkah-langkah penelitian pengembangan untuk menghasilkan produk yang telah dilakukan, maka di dapat produk akhir berupa model permainan sunda manda puzzle yang sesuai dengan karakterisitik siswa Sekolah Dasar. Indikator keberhasilan produk ini ialah berupa lembar penilaian hasil pengamatan terhadap seluruh subyek yang diujicobakan dalam penelitian ini.

Dipublikasikan Oleh :

UPT Publikasi dan Pengelolaan Jurnal

Universitas Islam Kalimantan Muhammad Arsyad Al-Banjari Banjarmasin 
Respon siswa terhadap aspek kognitif, afektif, dan psikomotor setelah menggunakan model permainan sunda manda puzzle menunjukan bahwa data responden siswa yang diambil dengan indikator kognitif respon positif sebesar $97,34 \%$ respon negatif sebesar 2,66\%. Indikator psikomotor respon positif sebesar $93,43 \%$, respon negatif sebesar 6,57\%. Indikator afektif respon positif sebesar $94,62 \%$,respon negatif sebesar $5,38 \%$.

Berdasarkan hasil analisis data ketertrimaan produk dapat disimpulkan bahwa respon siswa terhadap permainan sunda manda puzzle untuk optimalisasi kemampuan motorik dan pembentukan karakter cermat dalam pembelajaran penjasorkes di SD masuk dalam kategori sangat baik yaitu $93,58 \%$

Intensitas fisik atau keaktifan gerak peserta didik dapat dilihat dengan penghitungan denyut nadi, dimana penghitungan denyut nadi dilakukan dua tahap yaitu sebelum melakukan pembelajaran penjasorkes dan sesudah melakukan pembelajaran.

Hasil denyut nadi dari 79 responden sebelum mengikuti pembelajaran dan sesudah mengikuti pembelajaran permainan sunda manda puzzle didapatkan hasil sebagai berikut: (1) denyut nadi minimal sebelum mengikuti pembelajaran sunda manda puzzle sebesar $60 \mathrm{bpm}$ (beats per minute), denyut nadi maksimal sebelum mengikuti pembelajaran sebesar $86 \mathrm{bpm}$, serta ratarata denyut nadi sebelum mengikuti pembelajaran sebesar 72,06. (2) denyut nadi mainimal sesudah mengikuti pembelajaran sunda manda puzzle sebesar $102 \mathrm{bpm}$, denyut nadi maksimal sesudah mengikuti pembelajaran permainan sunda manda puzzle $138 \mathrm{bpm}$, serta rata-rata denyut nadi sesudah mengikuti pembelajaran permainan sunda manda puzzle sebesar 117,96 . Sehingga dapat disimpulkan kenaikan denyut nadi dengan rata-rata 64,01\%.

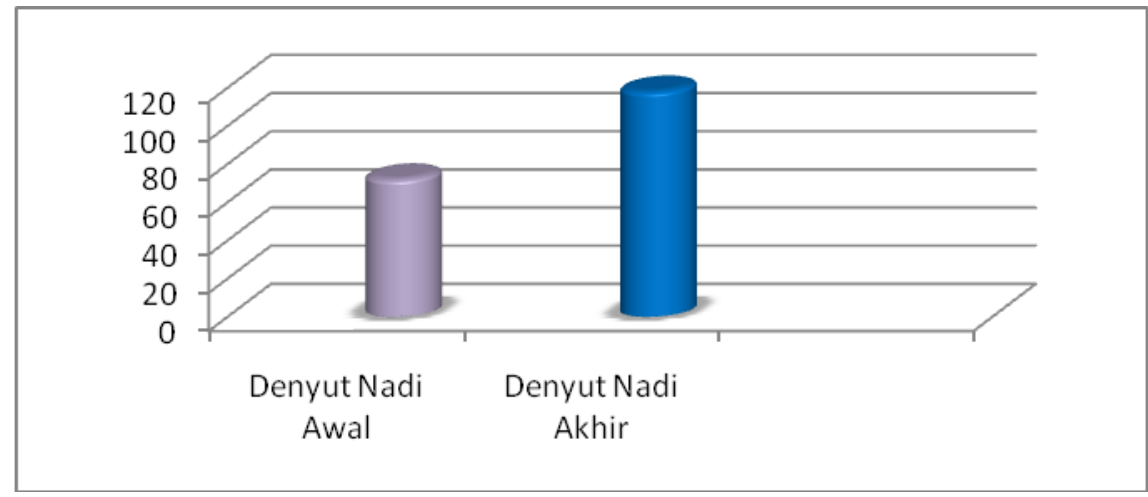

Gambar 1. Grafik peningkatan denyut nadi siswa setelah melakukan permainan sunda manda puzzle

\section{PENUTUP}

\section{KESIMPULAN}

Permainan sunda manda puzzle di kemas secara menarik dengan peraturan permainan dan alat-alat yang digunakan di sesuaikan dengan kebutuhan siswa SD. Permainan sunda manda puzzle aman dimainkan dan alat-alat yang digunakan relatif murah dan mudah didapat. Pengembangan permainan sunda manda puzzle untuk optimalisasi kemampuan motorik dan pembentukan karakter cermat dalam pembelajaran penjasorkes di SD dapat membantu guru penjasorkes sebagai salah satu alternative bahan ajar dalam materi permainan tradisional di sekolah untuk meningkatkan kebugaran jasmani siswa peningkatan dalam setiap ranah tujuan pendidikan yaitu aspek psikomotor, kognitif, dan afektif. Dengan demikian produk akhir Pengembangan permainan sunda manda puzzle untuk optimalisasi kemampuan motorik dan pembentukan karakter cermat dalam pembelajaran penjasorkes di SD sesuai dengan karakteristik siswa SD dan efektif digunakan dalam pembelajaran penjasorkes dalam materi permainan tradisional.

Dipublikasikan Oleh : 


\section{SARAN}

Model permainan sunda manda puzzle sebagai produk yang telah dihasilkan dalam penelitian ini dapat digunakan untuk alternative bahan ajar oleh guru penjasorkes di Sekolah Dasar dan dapat meningkatkan aspek psikomotor, kognitif dan afektif siswa dalam proses pembelajaran penjasorkes. Berpijak dari simpulan diatas maka diajukan saran sebagai berikut :

1. Bagi guru Penjasorkes di Sekolah Dasar dapat menggunakan model permainan sunda manda puzzle sebagai media pembelajaran khususnya pada materi permainan tradisional, karena dapat meningkatkan aspek kognitif, psikomotor, dan afektif.

2. Permainan sunda manda puzzle ini dirancang berdasarkan kebutuhan dan karakterisitik siswa Sekolah Dasar yang membuat siswa aktif bergerak, maka dari itu alat-alat yang digunakan serta peraturan permainan di sesuaikan dengan kebutuhan siswa Sekolah Dasar.

\section{REFERENSI}

Achroni, K. (2012). Mengoptimalkan Tumbuh Kembang Anak Melalui Permainan Tradisional. Javalitera.

Anomin. (2013). Pengertian Dan Sejarah Engklek. http://www.anakbawangsolo.org/2013/07/pengertian-dan-sejarah-engklek-sunda.html. Diakses tanggal 13 Agustus 2020

Arikunto, S. (2010). Prosedur Penelitian Suatu Pendekatan Praktik. Rineka Cipta.

Haerani. 2012. http://journal.uny.ac.id/index.php/jpka/article/view/1290 Membangun Karakter Anak Melalui Permainan Anak Tradisional. Diakses pada tanggal 1Agustus 2020.

Kusmiyati, Soegiyanto, \& Rahayu, S. (2014). PENGEMBANGAN MODEL MODIFIKASI PERMAINAN BOLAVOLI MINI “ SERPASSRING ” PEMBELAJARAN PENJASORKES SD KELAS V Abstrak. 3(2).

Miles, H. dan S. (2014). Analisis Data Kualitatif. Universitas Indonesia Pres.

Rosdiani, D. 2013. Perencanaan Pembelajaran Dalam Pendidikan Jasmani dan Kesehatan. Bandung :Alfabeta

Said Junaidi. 2011. Olahraga Usia Dini. Program Studi Ilmu Keolahragaan: Unuversitas Negeri Semarang.

Sukmadinata, N. S. (2010). Metode Penelitian Pendidikan. Remaja Rosda Karya.

Toho Cholik Mutohir. (2011). Berkarakter Dengan Berolahraga Berolahraga Dengan Berkarakter. Sport Media.

Dipublikasikan Oleh :

UPT Publikasi dan Pengelolaan Jurnal

Universitas Islam Kalimantan Muhammad Arsyad Al-Banjari Banjarmasin 